\title{
Razões da evasão: abandono escolar entre jovens no Brasil $^{1}$
}

André Salata*

\section{Resumo}

Apesar da expansão do sistema de ensino do país nas últimas décadas, assim como a meta de tornar compulsória e universal a frequência escolar também de jovens com idade correspondente ao Ensino Médio, entre estes ainda há uma parcela significativa que não frequenta a escola. 0 artigo tem como objetivo estudar os principais fatores associados à evasão escolar de jovens entre 15 e 17 anos de idade. Mais especificamente, analisamos o efeito da origem socioeconômica dos jovens, assim como de sua situação de trabalho, sobre as chances de evasão. Para isso, utilizamos dados provenientes da PNAD (IBGE) de 2015 e, também, do suplemente de 2006, a partir dos quais rodamos estatísticas descritivas e modelos logit multivariados. Os resultados alcançados evidenciam o forte efeito do background domiciliar e do trabalho intensivo - com carga horária acima de 20 horas semanais - sobre as chances de evasão, mas colocam dúvidas sobre as leituras que tomam a eventual necessidade de trabalhar como principal mediadora do efeito da origem social sobre a evasão de jovens.

\section{Palavras-chave}

Evasão Escolar. Ensino Médio. Origem Social. Trabalho. Desigualdades Sociais.

\begin{abstract}
Notwithstanding the expansion of the Brazilian's educational system in the last decades, as well as its goal of making compulsory and universal the school attendance of young people with a high school age, among these there is still a significant proportion that do not attend school. Thus, the article aims to study the main factors associated with school dropout among young people between 15 and 17 years of age. More specifically, we analyze the effects of the socioeconomic origin of young people, as well as their work situation, on the chances of evasion. Besides, we explore some data regarding the attested reasons for them to dropout school. We work with data from the National Household Sample Survey (PNAD) of
\end{abstract}

\footnotetext{
${ }^{1}$ Este trabalho é produto de projeto de pesquisa financiado pelo Conselho Nacional de Desenvolvimento Científico e Tecnológico (CNPq) por meio de uma bolsa de produtividade em pesquisa (PQ-nível 2), e foi desenvolvido no âmbito da Rede Observatório da Dívida Social das Universidades Católicas da América Latina (REDODSAL).

* André Salata é doutor em Sociologia, professor do Programa de Pós-Graduação em Ciências Sociais da Pontifícia Universidade Católica do Rio Grande do Sul (PUCRS) e bolsista de produtividade em pesquisa do CNPq. E-mail: andre_salata@yahoo.com.br.
} 
2015, and also from the PNAD 2006 supplement, from which we run descriptive statistics and multivariate logit models. The results corroborate the strong effect of family background and intensive work (with a workload of more than 20 hours per week) on the chances of dropout, but raise questions on the readings that take the possible need to work as the main mediator of the effect of social origin on youth evasion.

\section{Keywords}

School Dropout. High School. Social Origin. Employment. Social Inequalities.

\section{Introdução}

Em novembro de 2009 foi promulgada a emenda constitucional $n^{0} 59$, que determinava a ampliação da obrigatoriedade e gratuidade do ensino a todas as etapas da educação básica no Brasil, dos quatro aos dezessete anos de idade, prevendo sua implantação progressiva até o ano de 2016. Desse modo, a matrícula escolar obrigatória no Brasil, que até então ia dos 6 aos 14 anos de idade - o que corresponde ao Ensino Fundamental -, foi estendida também para as faixas etárias que correspondem à Pré-Escola (4-5 anos) e ao Ensino Médio (15-17 anos). O Plano Nacional de Educação (PNE), por sua vez, em consonância com a emenda constitucional $n^{\text {a }} 59$, entre suas 20 metas previa, justamente, universalizar, até 2016, o atendimento escolar da população de 4 a 5 (primeira meta) e de 15 a 17 anos (terceira meta), além de garantir a matrícula escolar de toda a população de 6 a 14 anos (segunda meta).

Se, por um lado - segundo dados de 2015, provenientes da Pesquisa Nacional por Amostra de Domicílios (PNAD), do Instituto Brasileiro de Geografia e Estatística (IBGE) -, a universalização das matrículas entre 6 e 14 anos já pode ser tomada como uma realidade (ficando em torno de $98 \%$ ), por outro lado, para as crianças de 4 a 5 anos, e também para os jovens de 15 a 17 anos de idade, o percentual dos que frequentam a escola girava, ainda em 2015, em torno de 85\%. Ou seja, há ainda muitos obstáculos para que aquelas metas, traçadas no PNE e promulgadas pela emenda constitucional $\mathrm{n}^{\circ} 59$, sejam alcançadas.

Neste artigo, estaremos interessados na faixa etária de 15 a 17 anos, tendo como objetivo identificar os principais fatores que ainda levam muitos desses jovens a não frequentar a escola, assim como suas motivações para não o fazerem. Tomaremos como foco principal a relação entre origem social e frequência à escola para os jovens naquela faixa etária, que idealmente 
corresponderia ao Ensino Médio, procurando analisar a força dessa relação, assim como os mecanismos e motivações que poderiam explicá-la, como a eventual necessidade de trabalhar.

Para isso, faremos uso dos dados da PNAD 2015 - a partir dos quais trabalharemos com modelos logit multivariados -, do suplemento da PNAD 2006 sobre educação - que traz informações sobre as motivações dos jovens para não frequentarem a escola - e, também, dos dados da PNAD 1995, a fim de elaborar uma breve análise descritiva das tendências observadas nas duas últimas décadas no que diz respeito à frequência escolar de crianças e jovens no Brasil. O presente artigo, dessa maneira, ao analisar a relação entre origem social e situação escolar, se insere tanto no campo dos estudos sobre estratificação social quanto no debate acerca da evasão escolar.

O trabalho se encontra organizado em cinco seções, além desta introdução. Na primeira delas procuramos oferecer um panorama geral da frequência à escola de crianças e jovens no Brasil das duas últimas décadas, além de estabelecer um diálogo com parte da bibliografia sobre o tema. $\mathrm{Na}$ seção subsequente, fazemos uma breve revisão a respeito das principais causas da evasão, assim identificadas pela literatura. Posteriormente, na seção seguinte, apresentamos as hipóteses a serem testadas, os dados, as variáveis e as técnicas utilizadas. Na outra seção, fazemos uso de modelos logit multivariados, a fim de identificar os principais fatores associados à evasão de jovens de 15 a 17 anos no Brasil, com atenção especial para as características de origem social e situação de trabalho; nessa seção também trazemos alguns dados a respeito das motivações dos jovens para não frequentarem a escola. Finalmente, nas conclusões, refletimos acerca dos principais resultados encontrados, à luz das questões previamente colocadas.

\section{Frequência à escola entre jovens de 15 a 17 anos no Brasil}

A escolaridade alcançada pelos indivíduos é, conforme já amplamente demonstrado por inúmeros estudos, no Brasil e no exterior, uma variávelchave para a explicação das desigualdades na sociedade contemporânea, constituindo-se fator crucial para as chances de os indivíduos conseguirem emprego, para o status da ocupação obtida e, também, para os rendimentos auferidos a partir da mesma (MENEZES-FILHO;FERNANDES;PICCHETTI, 2007). Assim, o tempo de permanência na escola é um elemento marcante no processo de reprodução das desigualdades, de modo que, quanto mais anos de estudo acumulados antes de o indivíduo deixar a escola, melhor 
tende a ser sua posição no mercado. Quanto mais cedo o jovem abandona a escola, por outro lado, maiores suas desvantagens na disputa pelas posições e recursos distribuídos pela sociedade (HASENBALG, 2003).

Mas não é somente em termos individuais que a evasão escolar traz prejuízos. Em um sentido mais coletivo, ela prejudica a própria acumulação de capital humano do país, colocando obstáculos a um desenvolvimento econômico de longo prazo (SCHULTZ, 1961). Além disso, a evasão também pode ser relacionada a diversos outros problemas sociais, tais como desemprego, pobreza, dependência da assistência pública, problemas de saúde, criminalidade, apatia política e social etc. (DE WITTE et al., 2013). Assim, é também do interesse coletivo que os indivíduos estendam sua permanência na escola, como condição necessária - mas não suficiente para um maior acúmulo de anos de estudo.

O Gráfico 1 traz o percentual de indivíduos que estudam, por idade (entre 10 e 30 anos), nas duas últimas décadas no Brasil. ${ }^{2}$

\section{Gráfico 1 - Percentual de Indivíduos que Estudam, por Idade (10 a 30 anos) -} Brasil, 1995, 2006 e 2015

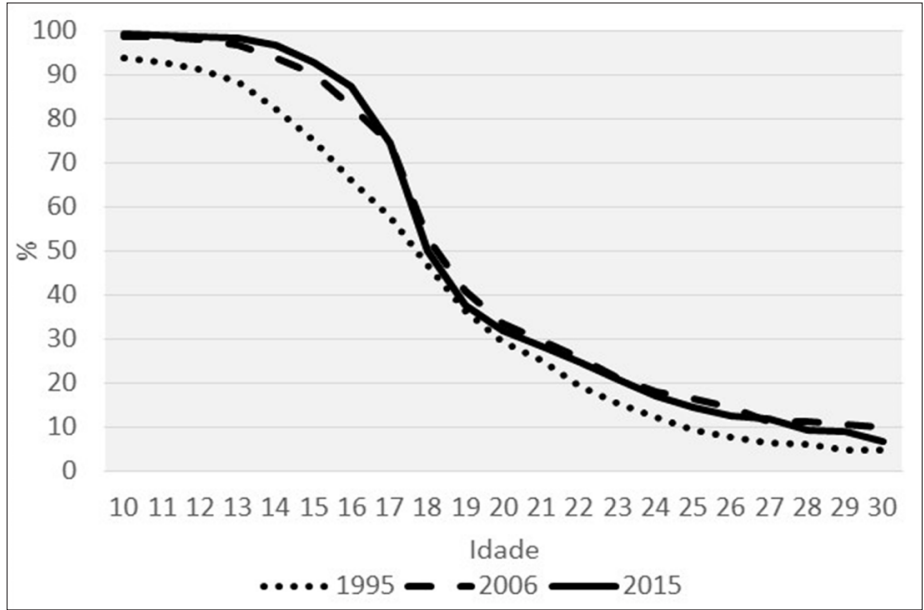

Fonte: Pesquisa Nacional por Amostra de Domicílios (PNAD-IBGE), 1995, 2006 e 2015. Tabulação: próprio autor.

Em primeiro lugar, notamos uma tendência clara e esperada em todo período que diz respeito à redução do percentual de estudantes conforme

\footnotetext{
${ }^{2}$ A fim de padronizarmos a amostra, excluímos as áreas rurais da região Norte, que foram incluídas nas PNADs apenas a partir de 2004. Além disso, a razão de utilizarmos os dados de 2006, e não de 2005 (que dividiria de modo mais exato as duas décadas tratadas), é que para aquele ano há um suplemento sobre educação, a partir do qual posteriormente iremos extrair informações relevantes para este artigo.
} 
crescem os anos de idade. Esse movimento, no entanto, não é linear. Até por volta dos 14 anos é bem reduzida a proporção de crianças e jovens fora da escola; a partir dessa idade, e principalmente quando chegamos em torno dos 16 anos, a frequência à escola cai de modo acentuado, desacelerando apenas por volta dos 20 anos. Verificamos, portanto, que a faixa etária tratada neste artigo, dos 15 aos 17 anos, é crucial nesse processo, já que é ali que um movimento mais proeminente de afastamento em relação à escola começa a ser observado.

Constatamos que desde 1995 houve melhoras nesse sentido, já que a frequência à escola passou a ser maior para todas as idades, principalmente entre os mais jovens (até 18 anos), o que ilustra uma tendência a deixarem a escola mais tarde. Mais especificamente, para a faixa etária que nos interessa aqui (15-17 anos), o percentual de jovens que não estudava cai de $33 \%$, em 1995, para 14\% em 2015. Em termos absolutos, em 2015 havia no Brasil, aproximadamente, 1.5 milhão de jovens nessa faixa etária fora da escola. ${ }^{3}$

No entanto, como pode ser visto no Gráfico 2 , as propensões a continuar na escolar variam bastante de acordo com o estrato socioeconômico dos jovens.

Gráfico 2 - Percentual de Indivíduos que Estudam, por Idade (10 a 30 anos), por Quintis de Renda Domiciliar Per Capita - Brasil, 2015

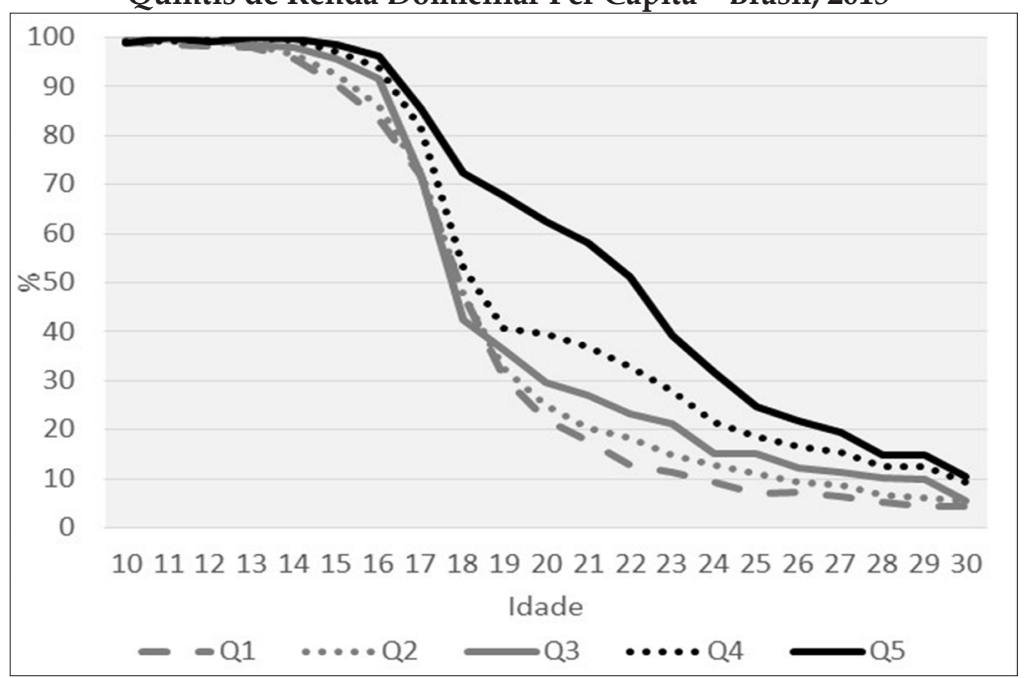

Fonte: Pesquisa Nacional por Amostra de Domicílios (PNAD-IBGE), 2015.

Tabulação: próprio autor

\footnotetext{
${ }^{3}$ Apesar de não termos dados longitudinais, e por isso não podermos afirmar que os jovens que não estavam estudando no momento da pesquisa não iriam voltar à escola, temos boas razões para acreditar que essa interrupção levará a prejuízos de aprendizado e, em muitos casos, ao abandono definitivo, reduzindo os anos de estudo alcançados pelo indivíduo.
} 
Ao dividir a população pelos quintis de rendimento domiciliar per capita, o Gráfico 2 ilustra as diferenças socioeconômicas nas propensões a continuar estudando, de acordo com a idade. Fica evidente, conforme esperado, que os jovens provenientes dos quintis mais elevados tendem a estudar até idades muito mais avançadas do que os jovens dos quintis mais baixos.

É interessante notar que essas desigualdades começam a se manifestar entre os 15 e 17 anos de idade, tornando-se mais acentuadas entre os 19 e 25 anos. Com efeito, se pensarmos na reprodução das desigualdades enquanto um processo de acúmulo de vantagens e desvantagens ao longo do ciclo de vida (HASENBALG; SILVA, 2003), a faixa etária correspondente ao Ensino Médio se mostra um momento crucial. Constatamos, por exemplo, que enquanto no primeiro quintil $17 \%$ dos jovens entre 15 e 17 anos não estudavam em 2015, no quintil mais rico esse percentual caía para $7 \%$.

Desse modo, apesar de a evolução recente ser positiva, há ainda um considerável percentual de jovens entre 15 e 17 anos de idade fora da escola, especialmente entre as camadas socioeconômicas inferiores.

\section{Pesquisas anteriores sobre evasão}

O tema da evasão escolar tem sido objeto de intenso debate no campo da Sociologia e, também, da Educação. Desde meados do século passado, diversos estudos consistentes têm sido elaborados a fim de procurar melhor compreender esse fenômeno, com foco nas possíveis causas que levam muitos jovens a deixar a escola antes de completarem determinado nível de estudo. Apesar das enormes dificuldades encontradas para tratar desse tema, dada a sua complexidade, podemos afirmar que há certo acúmulo de conhecimento acerca do mesmo, de modo que a maior parte das pesquisas sobre esse tópico, a despeito de sua heterogeneidade e resultados algumas vezes incongruentes, convergem em alguns pontos relevantes (HUNT, 2008).

Primeiramente, no entanto, é preciso lembrar que há ainda certa disputa acerca da definição desse fenômeno, ou seja, sobre o que entendemos por evasão escolar. Como bem colocado por Dore e Lüscher (2013), poderíamos relacioná-lo a fatores muito diversos, tais como a saída do aluno de uma instituição, a sua saída do sistema de ensino como um todo, a não conclusão de certo nível de escolaridade, o abandono definitivo da escola, o afastamento temporário em relação à mesma etc. Neste artigo, como já deve 
estar claro, focamos no afastamento - temporário ou definitivo - do jovem em relação ao sistema de ensino. ${ }^{4}$

Em relação às convergências encontradas na bibliografia, destaco três pontos centrais. O primeiro deles é a constatação de que a evasão escolar não é resultado de uma decisão pontual e facilmente localizada no tempo e espaço, mas sim fruto de um processo de média ou longa duração (FINN, 1989; WEHLAGE, 1989; LAMBORN et al., 1992). A evasão deve ser entendida como etapa final de um processo de desengajamento do estudante em relação à vida escolar, tanto do ponto de vista acadêmico que se expressa no baixo rendimento e maior repetência - quanto social expresso na fragilidade dos laços estabelecidos naquele espaço em relação a outras redes nas quais os estudantes estão inseridos.

O segundo ponto de convergência é o reconhecimento de que são inúmeros os fatores que condicionam os indivíduos a permanecer ou abandonar a escola. Entre as causas desse fenômeno, podemos encontrar fatores psicológicos, características individuais adscritas, atributos da família de origem, padrões de comportamento e atividades dentro da escola, características das próprias instituições de ensino, qualidades da vizinhança onde o jovem reside, condições do mercado de trabalho, entre outros (DE WITTE et al., 2013).

Dada a complexidade do fenômeno em foco, modelar seus determinantes se torna uma tarefa bastante árdua. De acordo com Rumberger (1983), relações de causalidade poderiam ser mais facilmente inferidas para fatores exógenos - como background familiar, localização geográfica e atributos individuais adscritos -, já que esses seriam fixos e determinados bem antes do momento da evasão. Já para fatores endógenos ${ }^{5}$ - como habilidades acadêmicas, aspirações, rendimento escolar, entre outros -, como esses tendem a ocorrer concomitantemente ao processo de evasão, seria muito mais difícil estabelecer tais relações.

Ainda de acordo com Rumberger (1983), a fim de determinar a magnitude dos efeitos de cada um desses fatores sobre a probabilidade de

\footnotetext{
${ }^{4}$ Com os dados que utilizamos, provenientes da PNAD, seria inviável estabelecer tais distinções. Desse modo, trabalhamos com o conceito de evasão como a condição do jovem que não frequentava a escola no momento da pesquisa. O fenômeno aqui mensurado, portanto, engloba tanto o abandono - situação na qual o jovem se matriculou em determinada série no início do ano letivo, tendo posteriormente deixado de frequentar a escola naquele ano quanto a evasão propriamente dita - quando o jovem que foi à escola em um dado ano não chega nem mesmo a se matricular no início do ano letivo seguinte (BARROS, 2017).

${ }^{5}$ Utilizo aqui a diferenciação estabelecida pelo próprio Rumberger (1983), entre fatores endógenos e exógenos.
} 
evasão, haveria duas estratégias possíveis: trabalhar somente com fatores exógenos, o que permitiria verificar os efeitos totais dos mesmos; ou inserir também fatores endógenos, que em grande medida exercem a função de mediadores entre as variáveis exógenas e a variável dependente. Nessa segunda estratégia, como resultado, temos os efeitos líquidos dos fatores exógenos e endógenos. Dado o interesse da presente pesquisa e a natureza dos dados em mãos, em nossa análise trabalharemos somente com fatores exógenos.

Chegamos, assim, ao terceiro ponto de convergência dos estudos sobre o tema, que se refere ao peso daqueles inúmeros fatores sobre as chances de evasão. A esse respeito ainda há muitas divergências, até mesmo em função das diferentes realidades que os estudos se dedicaram a analisar. No entanto, e apesar dessas divergências, há alguns resultados que aparecem com certa constância nessas pesquisas.

Segundo Rumberger (2001), ${ }^{6}$ o background familiar tem se mostrado o elemento mais relevante para predizer a evasão, destacando-se a escolaridade dos pais, os rendimentos, as condições de moradia, a estrutura familiar e a localização geográfica. Como a origem social está relacionada à localização geográfica em nível nacional e, em grande medida, condiciona o local de moradia no nível intramunicipal, ela é capaz de condicionar o acesso dos jovens à escola por meio da oferta disponível de unidades escolares e vagas. Entretanto, mesmo quando as variáveis geográficas são mantidas constantes, o nível socioeconômico da família de origem tende a se mostrar um dos fatores explicativos mais importantes sobre a evasão.

Diversos mecanismos causais poderiam ser imaginados a fim de explicar a relação entre o background domiciliar e as chances de evasão.

Sobre o efeito do nível de rendimentos da família de origem, é possível que jovens moradores de domicílios com menos recursos econômicos apresentem maiores chances de evasão, entre outras razões, em função da maior necessidade de complementarem a renda domiciliar. Nessa leitura, haveria uma estreita relação entre o background econômico, a eventual necessidade de o jovem complementar o orçamento familiar por meio de seu trabalho, e o consequente desengajamento em relação à esfera escolar. Aqui, o trabalho do jovem seria um dos principais mediadores entre a situação econômica familiar e a evasão, sendo a insuficiência de renda a causa última desse fenômeno, já que tornaria muito altos os custos de

\footnotetext{
${ }^{6}$ Para uma revisão sistemática dos resultados de pesquisas anteriores sobre o tema, ver também De Witte et al. (2013).
} 
dedicar-se exclusivamente à escola para os jovens provenientes de famílias com menor aporte econômico.

Entre as razões mencionadas pela literatura para o efeito do nível educacional da família de origem, poderíamos reduzir as explicações a dois tipos: aquelas que focam no papel da socialização e aquelas que têm na racionalidade o seu princípio. Entre as últimas, encontra-se a ideia de que pais mais escolarizados teriam maior conhecimento acerca da importância da escola, e por isso seus filhos apresentariam menores chances de evasão; já para o primeiro tipo de explicação, familiares mais ou menos escolarizados serviriam como modelos de papéis sociais, a partir dos quais os jovens desde sua infância - internalizariam a relevância da escola, seu valor e a possibilidades de obter sucesso via sistema escolar. Além disso, jovens provenientes de famílias com maior escolaridade tenderiam a apresentar maior familiaridade com a cultura escolar, melhor desempenho, menores chances de repetência e, consequentemente, maior engajamento escolar e menor propensão à evasão.

Ainda, entre os fatores de cunho institucional, características ligadas às escolas (rede de ensino, composição dos alunos, razão professor/alunos, estrutura física, qualidade dos professores conforme percebida pelos alunos e o clima escolar) e à vizinhança (recursos no local, influência dos pares, modelos de papel social e oportunidades de emprego) também se mostram relevantes. Já entre os fatores de cunho individual, que em grande medida fazem a mediação entre os fatores institucionais e a permanência ou evasão, destacam-se o desempenho acadêmico, a troca de escolas, a frequência às aulas, a disciplina do estudante dentro da escola, as aspirações educacionais e ocupacionais, a repetência e, finalmente, o sexo do estudante - de modo que mulheres apresentam menor tendência à evasão. ${ }^{7}$

É importante lembrar que comportamentos fora da escola também estão diretamente ligados às chances de evasão, tais como a gravidez precoce, o matrimônio e a participação no mercado de trabalho. Sobre o trabalho dos jovens, em outros países tem sido constatado que seu efeito sobre as chances de evasão, no sentido de aumentá-las independentemente dos demais fatores, é condicionado pelo tipo de emprego, estabilidade e, principalmente, pela intensidade da ocupação. Resultados de pesquisas conduzidas em outros países mostram que, enquanto jovens com carga horária de trabalho mais baixa (até 15 ou 20 horas semanais) chegam a ter

\footnotetext{
${ }^{7}$ Quanto ao efeito de raça, identificamos algumas divergências na literatura (DE WITTE et al., 2013).
} 
resultados escolares superiores aos jovens que não trabalham, aqueles com carga horária de trabalho mais elevada (acima de, aproximadamente, 20 horas semanais) tendem a apresentar pior desempenho escolar e maiores chances de evasão (WARREN, 2003, 2002; MCNEAL, 1997).

Duas possíveis explicações têm sido aventadas para o efeito de trabalhar sobre as chances de evasão (WARREN, 2002). A primeira delas, e mais convencional, é o modelo de "soma-zero", que assume que o tempo e a energia empregados no trabalho são subtraídos do tempo e energia que seriam gastos em atividades relacionadas à escola (presença nas aulas, estudo, preparação para provas, atividades extraclasse etc.) caso o jovem não trabalhasse. Quanto maior a carga horária de trabalho, menos tempo e energia ficariam disponíveis para as atividades escolares, o que acabaria por prejudicar o desempenho escolar, o engajamento do jovem na escola e, consequentemente, aumentaria suas chances de evasão.

Uma abordagem alternativa, denominada por Warren (2002) de "orientação primária", tem como fundamento não a alocação de recursos escassos (tempo e energia), mas sim fatores psicológicos e sociais que condicionariam a escolha dosjovens entre a escola e o trabalho. O pressuposto básico aqui é que estudantes cuja orientação estivesse mais voltada à escola tenderiam a apresentar melhor rendimento escolar, não importando sua situação de trabalho. Já estudantes com uma orientação menos voltada à escola tenderiam a obter um rendimento escolar menos satisfatório, independentemente de trabalharem ou não. A situação de trabalho, por sua vez, seria mero sintoma, resultante da importância conferida à escola (versus trabalho) pelo jovem, não havendo, portanto, uma relação causal direta entre as horas despendidas no trabalho e o rendimento escolar e/ou as chances de evasão.

Apesar de suas diferenças, de algum modo ambas as abordagens assumem haver também uma relação entre a entrada do jovem no mercado de trabalho e o background familiar. Na abordagem da "somazero", podemos argumentar, o ato de trabalhar estaria mais relacionado à carência de recursos econômicos e à necessidade de complementar o orçamento familiar, e atuaria como uma variável mediadora entre aquela carência, o pior desempenho escolar e a maior chance de evasão. $\mathrm{Na}$ segunda perspectiva, da "orientação primária", a entrada no mercado de trabalho seria - assim como a evasão -, mais consequência do que causa do pior rendimento escolar. Este último, por sua vez, seria em grande medida condicionado pela origem social, especialmente pelo nível educacional do núcleo familiar. 


\section{Hipóteses, dados e métodos}

No Brasil, quando comparamos com a extensa bibliografia internacional, constatamos uma carência de estudos mais abrangentes sobre o tema, em especial a respeito da evasão no Ensino Médio (SILVA, 2016; DORE; LÜSCHER, 2013). Como consequência, temos pouco conhecimento acumulado sobre os fatores associados à evasão escolar e o peso de cada um para a explicação e esclarecimento daquele fenômeno. ${ }^{8}$

Entre os estudos já realizados no país, muitos já apontaram as condições de vida da família de origem - ou nível socioeconômico -, a escolaridade da mãe, o tamanho e o tipo de família como alguns dos principais fatores explicativos da permanência na escola (BRANDÃO, 1983; LOPEZ DE LEON; MENEZES-FILHO, 2002). Uma leitura frequente sobre o fenômeno no país é que a evasão escolar seria fruto, principalmente, da necessidade de os jovens entrarem no mercado de trabalho a fim de colaborar com o orçamento familiar por meio do rendimento auferido (ARROYO, 1993; MEKSENAS, 1998). ${ }^{9}$ Tal abordagem se faz presente, também, em reportagens publicadas em jornais e revistas de grande circulação e na imprensa de um modo geral, que nos últimos anos chegou a dedicar um importante espaço ao tema da evasão escolar de jovens. ${ }^{10}$

Com efeito, o principal objetivo da análise conduzida neste trabalho é identificar os principais fatores associados à evasão escolar de jovens entre

\footnotetext{
${ }^{8}$ Para uma revisão mais abrangente da bibliografia nacional sobre o tema, ver Tavares Júnior, Santos e Maciel (2017).

${ }^{9}$ O estudo de Neri (2009), ao tratar das motivações de crianças e jovens para abandonar a escola, destaca o desinteresse pela mesma como a principal razão para a evasão e, apesar de suas limitações, oferece um interessante contraponto àquelas leituras mais voltadas à necessidade de trabalhar como explicação central daquele fenômeno.

${ }^{10}$ Exemplos de reportagens publicadas nos últimos anos sobre esse tema podem ser encontrados em:

- “Com evasão escolar empacada, país levaria 200 anos para incluir jovens”. Folha de São Paulo (17/10/2017). Disponível em: < http://www1.folha.uol.com.br/educacao/2017/10/1927604com-evasao-escolar-empacada-pais-levaria-200-anos-para-incluir-jovens.shtml>.

- "Brasil tem 2,5 milhões fora da escola; trabalho é principal razão para abandono". Gazeta do Povo (15/08/2017). Disponível em: <http://www.gazetadopovo.com.br/ educacao/brasil-tem-25-milhoes-fora-da-escola-trabalho-e-principal-razao-para-abandono7g4ljozkru2w9y6wu1hjag3gc>.

-"Por que o jovem não conclui o Ensino Médio?". Carta Educação (04/08/2016). Disponível em: <http://www.cartaeducacao.com.br/reportagens/por-que-o-jovem-nao-conclui-oensino-medio/ $>$.

- "Brasil encara a batalha para prosperar no ensino médio". El País (23/02/2018). Disponível em: < https://brasil.elpais.com/brasil/2018/02/22/politica/1519256346_754753.html>.
} 
15 e 17 anos no Brasil contemporâneo. Mais especificamente, perguntamos qual o peso do perfil socioeconômico da família de origem desses jovens, e de sua participação no mercado de trabalho, sobre as chances de não frequentar a escola? Além disso, indagamos em que medida a eventual necessidade de trabalhar faria a mediação entre a origem social e a frequência à escola? Com o intuito de fornecer resposta a essas questões, testaremos as seguintes hipóteses:

Hipótese 01: mesmo quando mantemos constantes as características individuais, geográficas e de estrutura familiar, o nível de rendimentos e, principalmente, o nível de escolaridade da família de origem ainda se mostram muito relevantes para explicar as chances de evasão.

Hipótese 02: o fato de o jovem trabalhar eleva suas chances de evasão, especialmente quando o trabalho exige uma carga horária mais intensiva.

Hipótese 03: a situação de trabalho do jovem explica uma parcela significativa do efeito da origem socioeconômica sobre as chances de evasão.

Como vimos, há boas razões teóricas, em grande medida confirmadas por estudos empíricos já realizados, para acreditarmos que a origem social dos jovens seja um dos fatores mais relevantes a fim de explicar suas chances de evasão. Além disso, pesquisas anteriormente desenvolvidas mostram que a situação de trabalho dos jovens, quando exige uma carga horária mais intensiva, tende a influenciar positivamente as chances de abandono. No entanto, lançamos dúvidas sobre a ênfase de alguns estudos nacionais sobre a suposta necessidade de trabalho como importante mediador entre os efeitos de classe de origem e a frequência à escola.

A fim de testar nossas hipóteses, trabalharemos com modelos logit multivariados, tendo as chances de evasão escolar como variável dependente. O Quadro 1 descreve as variáveis utilizadas nos modelos: 
Quadro 1 - Descrição das Variáveis Utilizadas nos Modelos

\begin{tabular}{|c|c|c|c|}
\hline Variáveis & Descrição & Tipo & Categorias \\
\hline \multicolumn{4}{|l|}{ Dependente } \\
\hline Evasão & $\begin{array}{l}\text { Indica se o indivíduo não } \\
\text { frequentava a escola na } \\
\text { época da pesquisa }\end{array}$ & Dummy & $\begin{array}{l}\text { 0-Não frequenta } \\
\text { 1-Frequenta }\end{array}$ \\
\hline \multicolumn{4}{|l|}{ Independentes } \\
\hline Idade & Idade em anos & Dummies & $\begin{array}{l}0-15 \text { anos } \text { (referenda) } \\
1-16 \text { anos } \\
2-17 \text { anos }\end{array}$ \\
\hline Região & $\begin{array}{l}\text { Região geográfica de } \\
\text { residência }\end{array}$ & Dummies & $\begin{array}{l}0 \text { - Nordeste (referência) } \\
1 \text { - Norte } \\
2 \text { - Sudeste } \\
3 \text { - Sul } \\
4 \text { - Centro-Oeste }\end{array}$ \\
\hline Localização & $\begin{array}{l}\text { Tipo de área da } \\
\text { residência }\end{array}$ & Dummies & $\begin{array}{l}0 \text {-Rural \{referência) } \\
1 \text { - Urbano não } \\
\text { metropolitano } \\
2 \text { - Urbano metropolitano }\end{array}$ \\
\hline Sexo & $\begin{array}{l}\text { Indicadora de sexo } \\
\text { feminino }\end{array}$ & Dummy & 0-Masculino 1-Feminino \\
\hline Cor & $\begin{array}{l}\text { Indicadora de pretos e } \\
\text { pardos }\end{array}$ & Dummy & $\begin{array}{l}\text { 0-Brancos } \\
\text { 1-Pretos e pardos }\end{array}$ \\
\hline $\begin{array}{l}\text { Tipo de } \\
\text { família }\end{array}$ & $\begin{array}{l}\text { Indicadorade famiia } \\
\text { monoparental }\end{array}$ & Dummy & $\begin{array}{l}0 \text { - Não-monoparental } \\
\text { 1-Monoparental }\end{array}$ \\
\hline $\begin{array}{l}\text { Número de } \\
\text { filhos }\end{array}$ & $\begin{array}{l}\text { Número de filhos com } \\
\text { até } 13 \text { anos de idade no } \\
\text { domicilio }\end{array}$ & Discreta & Número de filhos \\
\hline Escolaridade & $\begin{array}{l}\text { Maior escolaridade } \\
\text { (em anos) entre chefe e } \\
\text { cônjuge (quando houver) }\end{array}$ & Discreta & $\begin{array}{l}\text { Anos de estudo } \\
\text { completos }\end{array}$ \\
\hline Renda & $\begin{array}{l}\text { Renda mensal domiciliar } \\
\text { per capita (sem } \\
\text { considerar a renda } \\
\text { proveniente do trabalho } \\
\text { do jovem, quando } \\
\text { houver), dividida por } 100\end{array}$ & Contínua & $\begin{array}{l}\text { Renda em reais }\{\mathrm{RS}) \text {, } \\
\text { dividida por } 100\end{array}$ \\
\hline Trabalho & $\begin{array}{l}\text { Indica se o jovem } \\
\text { trabalha, e qual sua carga } \\
\text { horária semanal }\end{array}$ & Djmmies & $\begin{array}{l}0 \text { - Não trabalha } \\
\text { (referência) } \\
1 \text { - Trabalha (até } 20 \text { horas) } \\
2 \text { - Trabalha (mais de } 20 \\
\text { horas) }\end{array}$ \\
\hline
\end{tabular}

\section{Fonte: Elaborado pelo autor.}


Entre as variáveis independentes temos, primeiramente, um conjunto de dummies indicadoras de idade, que servirão como controle. Esperamos que idades mais avançadas estejam associadas a maiores chances de evasão. Em seguida, temos duas variáveis que visam capturar os efeitos da localização geográfica do domicílio: a região geográfica e o tipo de área - se rural, urbana não metropolitana ou urbana metropolitana. Os eventuais efeitos dessas variáveis servem como bons indicadores de possíveis deficiências na oferta de escolas e vagas, assim como da atratividade do mercado de trabalho nessas áreas.

Duas variáveis dizem respeito a características individuais adscritas, quais sejam, o sexo e a cor dos jovens. Se na literatura internacional, como vimos, há muitas discordâncias sobre o efeito de raça, é comum o resultado de que mulheres apresentem menores chances de evasão. Já as variáveis do tipo de família e número de filhos trazem a composição do domicílio para nossa análise, o que, segundo aquela literatura, tem se mostrado uma informação bastante relevante. Assim, é esperado que jovens provenientes de famílias ${ }^{11}$ com mais filhos e/ou monoparentais apresentem maiores desvantagens, já que tendencialmente receberiam menos atenção dos responsáveis (SILVA, 2003).

A variável de renda indica o nível de recursos econômicos da família de origem dos jovens, como de praxe na bibliografia sobre estratificação e desigualdades. Neste artigo estaremos trabalhando com a renda domiciliar per capita da residência dos mesmos, dividida por 100 - a fim de facilitar a leitura dos coeficientes do modelo. A fim de melhor capturar esse efeito da origem social, o cálculo da renda domiciliar per capita foi realizado sem considerar a eventual renda proveniente do trabalho do jovem. Já o nível de escolaridade da família de origem é mensurado a partir das informações dos responsáveis. Mais precisamente, utilizaremos os anos de estudo completos para o responsável pelo domicílio ou seu cônjuge (quando houver), considerando apenas aquele que apresentar maior escolaridade. De acordo com os pressupostos teóricos já mencionados, esperamos que, quanto menor o aporte de recursos econômicos e culturais, maiores sejam as chances de evasão.

Finalmente, nossa última variável independente indica não somente se o jovem trabalha, mas também a sua carga horária semanal, discriminando

\footnotetext{
${ }^{11}$ Apesar de nos referirmos muitas vezes às famílias, na verdade toda a análise é realizada a partir de informações do domicílio, que por vezes pode abrigar mais de uma família.
} 
entre indivíduos que trabalham até 20 horas e aqueles cuja carga horária fica acima de 20 horas semanais. Espera-se que o trabalho tenha efeito positivo sobre as chances de evasão, mas que, assim como verificado para outros países, esse efeito não seja linear, mostrando-se presente principalmente entre os jovens com carga horária semanal mais extensa. Como vimos, os eventuais efeitos do trabalho sobre a frequência à escola poderiam ser explicados em função da alocação de tempo e energia na ocupação em detrimento dos estudos, ou, então, como indicador do grau de centralidade atribuído pelos jovens e/ou suas famílias à escola em relação ao trabalho (WARREN, 2003).

Quanto ao recorte utilizado, trabalhamos somente com jovens entre 15 e 17 anos, que é a idade em que idealmente deveriam cursar o Ensino Médio. Além disso, para sermos capazes de considerar a origem social dos mesmos, tivemos que limitar nossa amostra aos jovens que estivessem no papel de filhos no domicílio, o que reduz o número de casos a quase $95 \%$ do total de jovens naquela faixa etária. ${ }^{12}$ Finalmente, restringimos nossa análise aos jovens que ainda não haviam completado o Ensino Médio, pois entendemos que não estar frequentando a escola tendo completado o mesmo é um fenômeno distinto da evasão antes de completar aquele nível de ensino.

\section{Resultados}

A fim de estimar as chances de evasão de acordo com as variáveis dependentes e assim testarmos nossas hipóteses, trabalhamos com modelos logit multivariados. ${ }^{13}$

Foram rodados seis modelos aninhados. ${ }^{14}$ Primeiramente, temos o modelo nulo, que inclui apenas a constante; já o "Modelo 1" adiciona a idade; o "Modelo 2" incorpora as variáveis geográficas; o "Modelo 3" traz também as variáveis individuais; o "Modelo 4" adiciona as informações de estrutura familiar; o "Modelo 5" inclui os indicadores de recursos econômicos e culturais da família de origem; finalmente, o "Modelo 6"

\footnotetext{
${ }^{12}$ Esse recorte, sem dúvidas, traz limitações à nossa análise, cujos resultados devem então ser tratados com cautela.

${ }^{13}$ Para uma exposição mais detalhada sobre este tipo de modelo, ver Powers e Xie (2008).

${ }^{14}$ Para rodar os modelos, fizemos uso dos pesos amostrais, sem, no entanto, realizar a expansão da amostra. Assim, os testes de hipóteses foram realizados com o número real de casos da amostra.
} 
adiciona as variáveis indicadoras de trabalho do jovem e sua eventual carga horária semanal. A Tabela 1 traz os coeficientes de cada um desses modelos, em razões de chance. ${ }^{15}$

Tabela 1 - Modelos Logit: razões de chance $[\exp (b)]$ para a evasão de jovens entre 15 e 17 anos de idade- Brasil, 2015

\begin{tabular}{|c|c|c|c|c|c|c|c|}
\hline Variáveis & Mod 0 & Mod 1 & Mod 2 & Mod 3 & Mod 4 & Mod 5 & Mod 6 \\
\hline Idade (16) & $\ldots$ & $1,610^{* * *}$ & $1,603^{* * *}$ & $1,614^{* * *}$ & $1,640^{* * *}$ & $1,653^{* * *}$ & $1,543^{* * *}$ \\
\hline Idade (17) & $\ldots$ & $3,008^{* * *}$ & $3,028^{* * *}$ & $2,988^{* * *}$ & $3.098^{* * *}$ & $3,099^{* * *}$ & $2,633^{* * * 8}$ \\
\hline Norte & $\ldots$ & $\ldots$ & $0,822+$ & $0,818+$ & $0,819+$ & 0,982 & 0,961 \\
\hline Sudeste & $\ldots$ & $\ldots$ & $0,785^{* *}$ & $0,849+$ & 0,897 & 1,129 & 1,054 \\
\hline Sul & $\ldots$ & $\ldots$ & 1,059 & $1,202+$ & $1,277^{*}$ & $1,641^{* * *}$ & $1.482^{* * *}$ \\
\hline Centro-Oeste & $\ldots$ & $\ldots$ & 0,981 & 1,014 & 1,079 & $1,5528^{* * *}$ & $1,370-$ \\
\hline Urbano & $\ldots$ & $\ldots$ & $0,759^{* *}$ & $0,791^{* *}$ & $0,799 *$ & $1203+$ & $1218^{*}$ \\
\hline $\begin{array}{c}\text { Urbano } \\
\text { metropolitano }\end{array}$ & $\cdots$ & $\cdots$ & $0,616^{* * *}$ & $0,636^{* * *}$ & $0,632^{* * *}$ & 1,111 & 1,160 \\
\hline Feminino & $\ldots$ & $\ldots$ & $\ldots$ & $0,537^{* * *}$ & $0,530^{* * *}$ & $0,520^{* * *}$ & $0,574^{* * *}$ \\
\hline $\begin{array}{c}\text { Pretos e } \\
\text { Pardos }\end{array}$ & $\cdots$ & $\cdots$ & $\ldots$ & $1,327^{* * *}$ & $1,246^{* *}$ & 1,005 & 1,013 \\
\hline Monoparental & $\ldots$ & $\ldots$ & $\ldots$ & $\ldots$ & $1,777^{\star * *}$ & $1,329 * * *$ & $1,304^{* * *}$ \\
\hline $\begin{array}{l}\text { Número de } \\
\text { filhos }\end{array}$ & $\cdots$ & $\cdots$ & $\cdots$ & $\cdots$ & $1,230^{* * *}$ & $1,107^{* * *}$ & $1.100^{* * *}$ \\
\hline Escolaridade & $\ldots$ & $\ldots$ & $\ldots$ & $\ldots$ & $\ldots$ & $0,877^{* * *}$ & $0,877^{* * *}$ \\
\hline Renda & $\ldots$ & $\ldots$ & $\ldots$ & $\ldots$ & $\ldots$ & $0,943^{* * *}$ & $0,944^{* * *}$ \\
\hline $\begin{array}{c}\text { Trabalho (até } \\
20 \mathrm{~h})\end{array}$ & $\cdots$ & $\cdots$ & $\cdots$ & $\cdots$ & $\cdots$ & $\cdots$ & $0,805+$ \\
\hline $\begin{array}{c}\text { Trabalho } \\
\text { (mals de 20h) }\end{array}$ & $\cdots$ & $\cdots$ & $\ldots$ & $\cdots$ & $\cdots$ & $\cdots$ & $2,962^{* * *}$ \\
\hline Constante & $0.106^{* * *}$ & $0.060^{* * *}$ & $0.088^{* * *}$ & $0.088^{* * *}$ & $0.046^{\star * *}$ & $0.152^{* * *}$ & $0,142^{* * *}$ \\
\hline $\mathrm{N}$ & 13.557 & 13.557 & 13.557 & 13.557 & 13.557 & 13.557 & 13.557 \\
\hline $\log N$ & -2487830 & -2419806 & -2402343 & -2366102 & -2324539 & -2206539 & -2149088 \\
\hline Model X² & $\ldots$ & $136048^{* * *}$ & $170974^{* * *}$ & $243456^{\star * *}$ & $326582^{* * *}$ & $562582^{* * *}$ & $677484^{* * *}$ \\
\hline LLR test & $\ldots$ & $\ldots$ & $34926^{* * *}$ & $72482^{* * *}$ & $83126^{* * *}$ & $236000^{* * *}$ & $114902^{* * *}$ \\
\hline $\mathrm{df}$ & 0 & 2 & 8 & 10 & 12 & 14 & 16 \\
\hline
\end{tabular}

Fonte: Pesquisa Nacional por Amostra de Domicílios (PNAD-IBGE), 2015.

Tabulação: próprio autor.

$+\mathrm{p}<=0,10 * \mathrm{p}<=0,05 *{ }^{*} \mathrm{p}<=0,01 * * * \mathrm{p}<=0,001$

Conforme pode ser verificado na parte inferior da tabela, todos os modelos apresentam poder de explicação significativamente maior que o

${ }^{15}$ Para obter as razões de chance, são calculados os exponenciais dos coeficientes dos modelos. 
modelo nulo. Além disso, o ajuste de cada um deles é significativamente melhor que aquele do modelo imediatamente anterior. Visando testar nossas hipóteses, estaremos especialmente interessados nos coeficientes dos "Modelo 5"- que inclui as informações de recursos econômicos e culturais - e, posteriormente, do "Modelo 6" - que adiciona a variável de trabalho.

Olhando primeiramente para o "Modelo 5", vemos que, conforme esperado, a idade apresenta forte efeito positivo sobre as chances de evasão, dado que jovens com 17 anos têm chances maiores que jovens de 15 anos de estarem fora da escola. ${ }^{16}$ A região de moradia também influencia significativamente nas chances de evasão ${ }^{17}$, de modo que, quando comparado com a região Nordeste (categoria de referência), moradores da região Sudeste, Sul e Centro-Oeste apresentam chances maiores. Além disso, morar em área urbana aumenta significativamente (em 20\%) as chances de evasão. ${ }^{18}$ Uma possível explicação para parte desses efeitos de região - com exceção do parâmetro relativo ao Centro-Oeste - e área poderia estar no maior poder de atratividade do mercado de trabalho sobre os jovens em regiões economicamente mais dinâmicas, elevando as chances de evasão. Essa interpretação, entretanto, é apenas em parte corroborada a partir das alterações desses parâmetros no "Modelo 06", quando inserimos a variável indicadora de trabalho, o que reduz os coeficientes relativos às regiões Sul e Sudeste, mas não aqueles indicadores de áreas urbanas.

Em conformidade com a bibliografia sobre o tema, as mulheres apresentam chances $48 \%$ menores de evasão do que os homens. Já a raça dos jovens, no entanto, passa a não exercer efeito significativo sobre as chances de evasão quando inserimos as variáveis de renda e escolaridade no modelo, estando esse resultando em consonância com parte da literatura internacional. A estrutura familiar, conforme esperado, tem efeito significativo sobre as chances de evasão. Para jovens em famílias monoparentais, estas são 32\% maiores; e a cada filho a mais no domicílio as chances aumentam em $10 \%$.

Finalmente, devemos olhar para os efeitos das variáveis indicadoras de recursos econômicos e culturais da família de origem. Mesmo mantendo

${ }^{16} \mathrm{~A}$ fim de interpretar as razões de chance em termos percentuais, basta aplicar a seguinte fórmula: $(\mathrm{x}-1)^{\star} 100$.

${ }^{17} \mathrm{O}$ teste para a significância estatística dos 4 parâmetros de região, em conjunto, rejeita a hipótese nula com $\mathrm{p}<0.001$.

${ }^{18}$ A moradia em região metropolitana, em relação a áreas rurais, também aumenta estas chances. No entanto, o coeficiente não se mostra significativo. 
constantes as demais variáveis do modelo, cada ano a mais de escolaridade do responsável reduz as chances de evasão em 13\%. Em relação aos rendimentos domiciliares, a cada 100 reais a mais de renda per capita, as chances de evasão diminuem em aproximadamente $6 \%$. Assim, encontramos efeitos fortes e significativos das informações de origem familiar sobre as chances de evasão.

A fim de melhor interpretarmos esses efeitos, faremos uso de probabilidades preditas a partir dos parâmetros do "Modelo 5". O gráfico abaixo traz as probabilidades para evasão (eixo vertical), de acordo com valores de renda domiciliar per capita (eixo horizontal) e escolaridade do responsável (discriminando cada uma das linhas). ${ }^{19}$ Desse modo, enquanto que a inclinação das retas representa graficamente o efeito da renda, a distância estre as mesmas ilustra o efeito da escolaridade.

Gráfico 3 - Modelos Logit: probabilidades preditas para a evasão de jovens entre 15 e 17 anos de idade, de acordo com escolaridade do responsável e renda familiar - Brasil, 2015

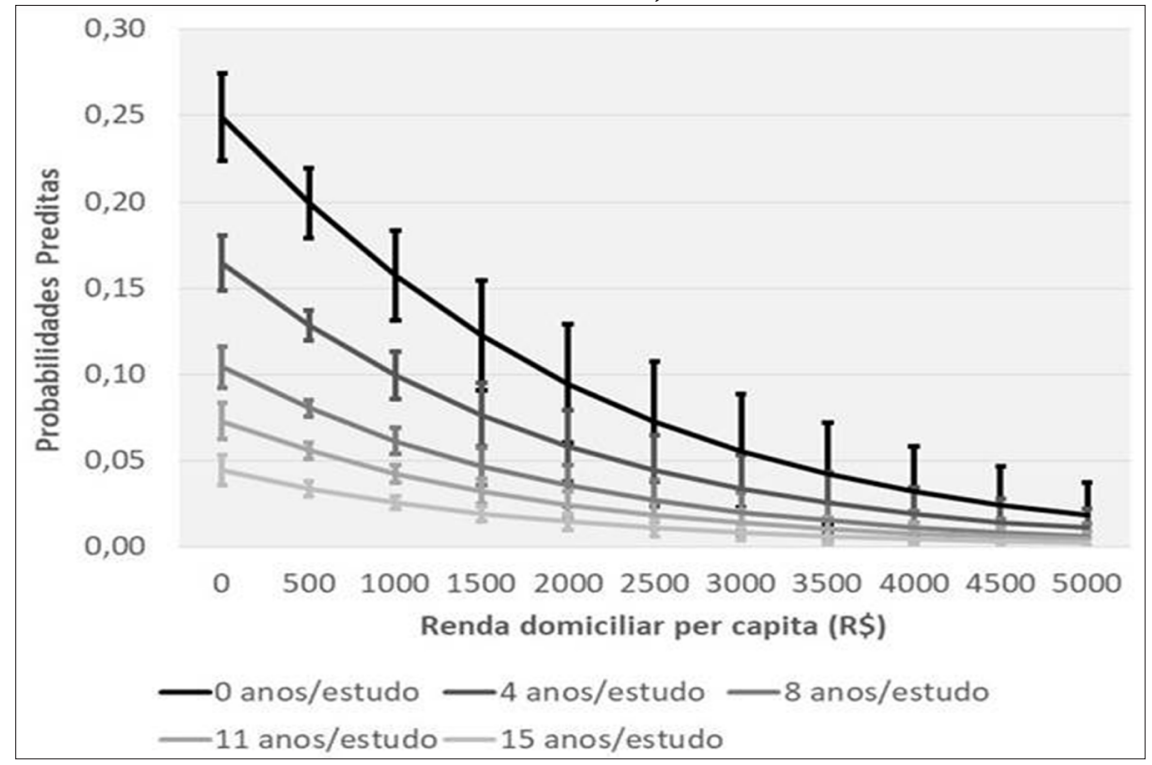

Fonte: Pesquisa Nacional por Amostra de Domicílios (PNAD-IBGE), 2015. Tabulação: próprio autor.

${ }^{19}$ Além disso, o gráfico também traz os intervalos de confiança $(90 \%)$ para cada uma das estimativas, representados pelos traços verticais cruzando as linhas. 
No Gráfico 3, podemos enxergar de modo mais claro os enormes efeitos que os recursos econômicos e culturais da família de origem exercem sobre as probabilidades de evasão dos jovens, mesmo quando mantemos constantes as demais variáveis. ${ }^{20}$ Além disso, e conforme esperado para esse tipo de modelo, as probabilidades não são lineares, de modo que as influências de renda e escolaridade variam de acordo com os valores da outra variável.

Segundo o modelo que estimamos, um jovem cujo responsável com maior escolaridade não tenha nem ao menos 1 ano de estudo completo, e cujo domicílio onde reside tenha renda per capita próxima de zero, tem probabilidade de 0,25 de não estar estudando. Para o mesmo nível de rendimentos, essa probabilidade cai para menos de 0,05 , caso a escolaridade do responsável seja de 15 anos, o que expressa o acentuado efeito do capital cultural sobre a evasão, e que pode ser visualizado na distância vertical que separa as linhas no campo mais à esquerda do gráfico. Conforme caminhamos em direção às famílias com maior aporte de rendimentos, na parte mais à direita, no entanto, a tendência observada é de redução acentuada da probabilidade de evasão para todos os perfis. Assim, mesmo que o responsável não tenha completado nenhum ano de estudo, a probabilidade de evasão é baixíssima, de 0,018, caso a renda per capita esteja em $\mathrm{R} \$ 5.000,00$. Portanto, como esperado, os efeitos das variáveis de background domiciliar são acentuados e se fazem sentir de modo mais proeminente entre os jovens com maiores probabilidades de evasão.

Os resultados até então analisados já são suficientes para corroborar nossa primeira hipótese de que os recursos econômicos e culturais da família de origem dos jovens apresentam forte influência sobre suas chances de evasão, independentemente das outras variáveis (individuais, geográficas e de estrutura familiar) também inseridas no modelo. Também já foi possível identificar os principais fatores que têm impacto naquelas chances, destacando-se, para além de escolaridade e renda, o número de filhos na família, a presença ou não de um cônjuge, o sexo e a região geográfica de residência.

Analisando agora os coeficientes do "Modelo 06", vemos, primeiramente,

\footnotetext{
${ }^{20}$ Para o cálculo das probabilidades preditas, os valores das demais variáveis foram fixados em suas respectivas médias. É importante lembrar, portanto, que o gráfico representa os efeitos de escolaridade e renda sobre indivíduos "médios" nas demais variáveis do modelo, e que os resultados apresentados seriam distintos caso fixássemos aquelas variáveis em valores diferentes.
} 
que o trabalho com carga horária menos intensa (até 20 horas) não eleva as chances de evasão. Pelo contrário, o fato de o jovem trabalhar com carga horária menos intensa está associado a uma chance $20 \%$ menor de evasão (resultado significativo ao nível de $p<=0,100$ ). Por outro lado, o fato de o jovem trabalhar mais de 20 horas por semana aumenta suas chances de evasão em 196\%. Ou seja, corroborando nossa segunda hipótese, e assim como também verificado em outros países (WARREN, 2003), o efeito de trabalhar sobre a frequência à escola é acentuado, mas se faz presente apenas para aqueles com carga horária mais elevada.

Na literatura sobre o tema encontramos algumas hipóteses explicativas para o fato de o trabalho tendencialmente elevar as chances de evasão apenas quando se trata de uma carga horária intensiva (D`AMICO, 1984; STEINBERG et al., 1993; McNEAL, 1997). A mais comum delas é a de que se, por um lado, trabalhos mais intensivos acabariam por fazer uso de tempo e energia que poderiam ser empregados em atividades escolares, por outro lado, a experiência de trabalho em si exigiria e cultivaria qualidades também valorizadas no universo escolar, como disciplina, perseverança e atitude colaborativa, por exemplo. Assim, até certo ponto, a experiência de trabalho poderia caminhar junto ao bom rendimento escolar, tornando-se prejudicial somente nos casos de carga horária mais intensiva, quando seus efeitos negativos anulariam os positivos.

Retomando a discussão apresentada anteriormente, vimos que uma das possíveis explicações para o efeito das características socioeconômicas da família de origem sobre a evasão seria a necessidade de trabalho dos jovens em famílias menos abastadas, a fim de complementar a renda domiciliar. Voltando à Tabela 1, no entanto, os coeficientes do nosso "Modelo 6" mostram que, mesmo quando inserimos uma variável indicando a situação de trabalho do jovem e a sua carga horária, os efeitos de escolaridade e renda continuam sendo significativos; mais do que isso, eles se mantêm praticamente inalterados em relação ao modelo anterior, o qual não incluía a variável trabalho, não sendo estatisticamente significativa a pequena diferença observada. ${ }^{21}$

Tal resultado pode ser tomado como evidência de que apenas uma parcela muito pequena, ínfima, e não significativa, dos efeitos de recursos econômicos e culturais da família de origem se dá por meio de uma suposta

${ }^{21} \mathrm{O}$ mesmo não acontece com os coeficientes de sexo e de região geográfica, que tendem a diminuir; o que pode ser tomado como evidência de que parte dos efeitos dessas variáveis passa pela variável indicadora de trabalho. 
pressão para que o jovem trabalhe. De tal modo, podemos afirmar que a maior parte do efeito da família de origem sobre a frequência à escola passa ao largo da participação dos jovens no mercado de trabalho.

Visando melhor analisar os efeitos do trabalho sobre a evasão, e também sua relação com os rendimentos e escolaridade da família de origem dos jovens, o Gráfico 4 traz mais algumas probabilidades preditas. Primeiramente, criamos três tipos socioeconômicos: Baixo (renda per capita de $\mathrm{R} \$ 500,00$ e 4 anos de estudo), Médio (renda per capita de $\mathrm{R} \$ 1.500,00$ e 8 anos de estudo) e Alto (renda per capita de $\mathrm{R} \$ 3.000,00$ e 12 anos de estudo). Em seguida, calculamos as probabilidades de evasão para cada um desses perfis, de acordo também com a situação de trabalho dos jovens. ${ }^{22}$

\section{Gráfico 4 - Modelos Logit: probabilidades preditas para a evasão de jovens} entre 15 e 17 anos de idade, de acordo com situação de trabalho e perfil socioeconômico da família - Brasil, 2015

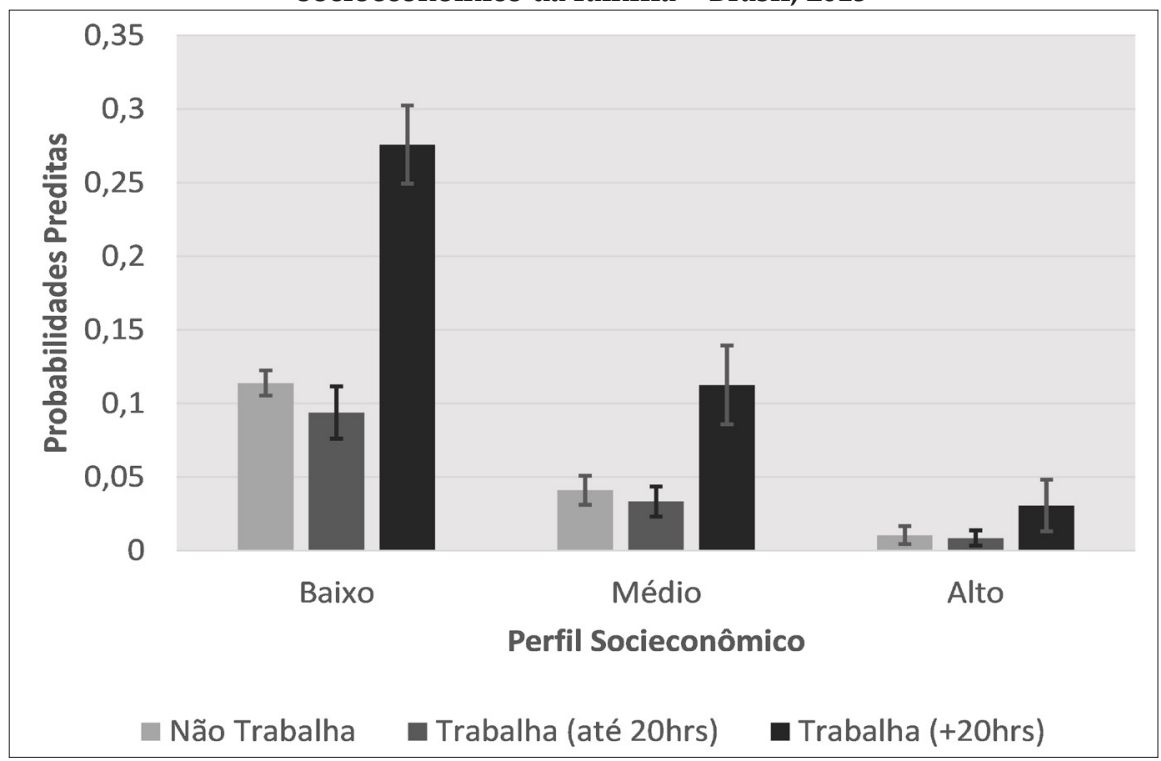

Fonte: Pesquisa Nacional por Amostra de Domicílios (PNAD-IBGE), 2015. Tabulação: próprio autor.

A diferença de altura entre as barras de um mesmo cluster (Baixo, Médio ou Alto) expressa graficamente o efeito de trabalhar e da carga horária de

\footnotetext{
${ }^{22}$ Para o cálculo das probabilidades preditas, os valores das demais variáveis foram fixados em suas respectivas médias.
} 
trabalho, e as diferenças de barras com a mesma coloração, entre os clusters, representam o efeito do nível socioeconômico. ${ }^{23}$

Alguns resultados ficam mais claros e evidentes a partir do gráfico. Primeiramente, que tanto o nível socioeconômico quanto o trabalho intensivo (mais de 20 horas semanais) possuem efeitos agudos sobre a probabilidade de evasão, de modo que esses efeitos se somam, atuam concomitantemente, não sendo possível tomar o trabalho como variável mediadora entre o background familiar e a evasão. Segundo, que o efeito do trabalho com carga horária elevada é consideravelmente maior para os jovens provenientes de famílias com perfil socioeconômico mais baixo, cujas probabilidades de abandono são mais altas. A título de ilustração, vemos que um jovem de perfil socioeconômico "Baixo" teria probabilidade de evasão na ordem de 0,11 ; e que esta saltaria para 0,27 caso o mesmo jovem trabalhasse com carga horária superior a 20 horas semanais. Finalmente, que mesmo quando comparamos situações semelhantes de trabalho, com carga horária análoga, continua havendo diferenças marcantes e significativas entre jovens provenientes de famílias com perfis socioeconômicos distintos. Por exemplo, entre os jovens que não trabalham, a probabilidade de evasão fica em 0,11 para o perfil "Baixo", 0,04 para o perfil "Médio", e 0,01 para o perfil "Alto".

Deste modo, se os resultados alcançados trazem evidências suficientemente fortes para corroborar as duas primeiras hipóteses anteriormente lançadas por nós, o mesmo não pode ser dito em relação à terceira. $\mathrm{O}$ fato de o jovem trabalhar, mesmo que de modo intensivo, não explica parcela significativa do efeito da origem socioeconômica sobre as chances de evasão. Na verdade, ambos os efeitos, de background familiar e de situação de trabalho, são acentuados e se somam, não sendo possível afirmar nem que a situação de trabalho seja um importante mediador entre nível socioeconômico e evasão, e nem que sua relação com esse fenômeno seja espúria, resultante dos efeitos combinados do background sobre as duas.

\section{Motivações da evasão}

Com o objetivo de melhor compreender os fatores associados à evasão, assim como os mecanismos através dos quais aqueles exercem seus efeitos

${ }^{23}$ Além disso, o gráfico também traz os intervalos de confiança $(90 \%)$ para cada uma das estimativas, representados pelos traços verticais na parte superior das barras. 
sobre a ação dos jovens, outro tipo de informação relevante pode ser as motivações alegadas pelos indivíduos para não estarem frequentando a escola (RUMBERGER, 1983). Felizmente, no ano de 2006, a PNAD trouxe também um suplemento em que era perguntado qual o principal motivo para a pessoa não frequentar a escola (se este fosse o caso). ${ }^{24}$

Entre as opções de resposta dadas aos entrevistados, constavam 16 possibilidades, que então agregamos em 5 categorias, conforme o Quadro 2:

Quadro 2 - Possíveis motivos para não frequentarem a escola

\begin{tabular}{|c|l|}
\hline Demanda & - Falta de documentação \\
(incapacidade) & - Não tem quem o(a) leve \\
& - Expunça ou incapacidade \\
\hline Demanda & - Concluiu a série ou curso desejado \\
(motivação) & - Não quis frequentar escola ou creche \\
\hline & - Os pais ou responsáveis não querem que frequente \\
\hline Demanda (renda/ & - - Tjudar nos afazeres domésticos \\
trabalho) & - Falta de dinheiro para as despesas escolares \\
& - Os pais ou responsáveis preferem que trabalhe \\
\hline & - Falta de transporte escolar \\
\hline Oferta & - Não existe escola ou creche perto de casa \\
\hline Outros motivos & - Falta de vaga na escola ou creche \\
\hline
\end{tabular}

Fonte: Elaborado pelo autor.

A primeira categoria diz respeito a jovens que não frequentavam a escola por algum impedimento específico, como doença, falta de documentação etc. A segunda diz respeito à não frequência escolar por falta de motivação dos próprios jovens ou de seus responsáveis. A terceira categoria se refere aos jovens que não frequentavam a escola em função de limitações financeiras e/ou necessidade de trabalhar, incluindo trabalho doméstico. A quarta engloba as razões voltadas a limitações de oferta, como a falta de vagas, escolas e transporte. Finalmente, a quinta e última categoria agrega os casos não contemplados pelas anteriores.

\footnotetext{
${ }^{24} \mathrm{O}$ entrevistado não era necessariamente o jovem, o que sem dúvida pode gerar algum viés nas respostas obtidas. Por esta razão, tais dados devem ser analisados com cautela.
} 
O Gráfico 5 traz a frequência percentual das motivações para jovens entre 15 e 17 anos não frequentarem a escola no Brasil, distribuídas pelos quintis de renda domiciliar per capita.

Gráfico 5 - Motivações para a evasão de jovens entre 15 e 17 anos de idade, por quintis de renda domiciliar per capita - Brasil, 2006

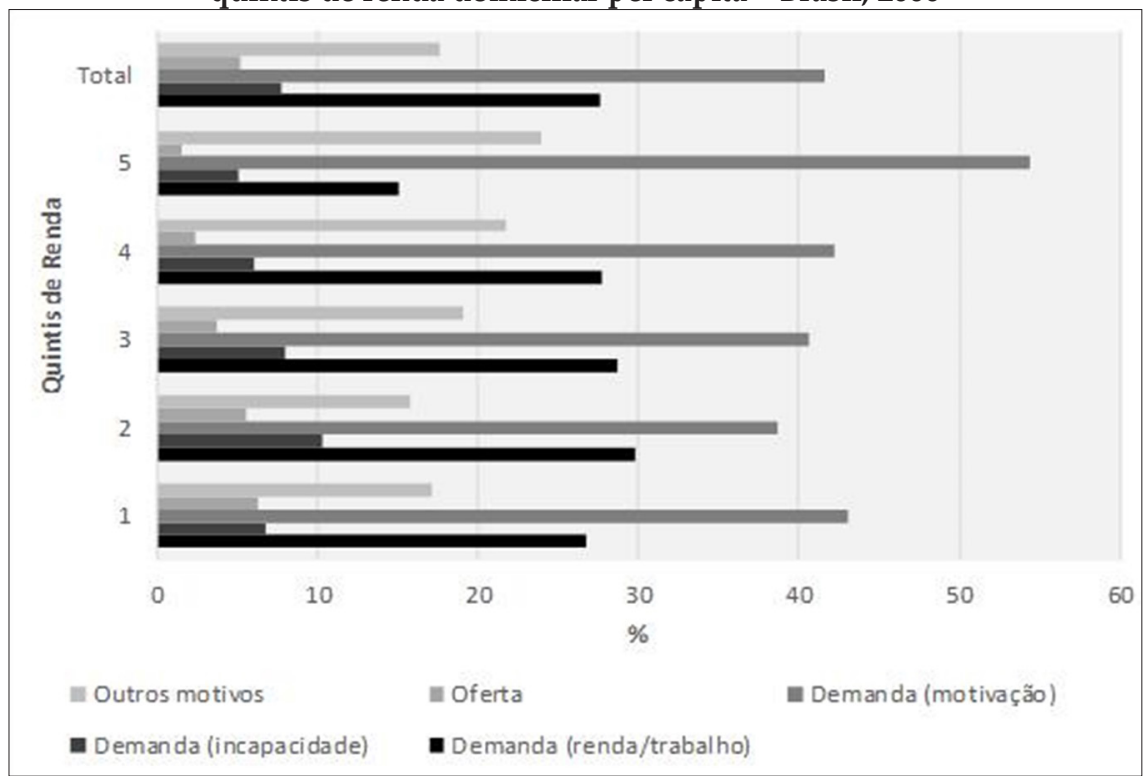

Fonte: Pesquisa Nacional por Amostra de Domicílios (PNAD-IBGE), 2006. Tabulação: próprio autor.

Um primeiro ponto a ser observado é o elevado percentual de respostas na categoria residual "outros motivos", o que imediatamente chama atenção para a complexidade desse fenômeno, a dificuldade de categorização desses motivos e, assim, as limitações metodológicas dessa abordagem.

No agregado total, o motivo mais citado para a evasão dos jovens é a falta de motivação, englobando mais de $41 \%$ dos casos. Em seguida, temos as limitações de rendimentos e necessidade de trabalhar, com $27 \%$. Outros motivos não englobados pelas demais categorias, por sua vez, correspondem a $17 \%$ dos casos. As incapacidades foram citadas por $7 \%$ dos entrevistados, e as deficiências na oferta escolar por aproximadamente 5\% dos mesmos. O padrão observado é semelhante para todos os quintis de renda, com exceção do quintil mais rico, em que o percentual de evasão em função de renda/trabalho é substantivamente menor, e o de evasão 
em virtude de falta de motivação é maior. Além disso, há uma tendência, também, de elevação da categoria residual entre os quintis mais ricos. Mas, de um modo geral, as razões alegadas para a evasão são semelhantes para todos os quintis, destacando-se, em primeiro lugar, a falta de motivação e, posteriormente, as carências econômicas e/ ou a necessidade de trabalhar.

É importante mencionar que, dentro dessas grandes categorias predominantes - Demanda (motivação) e Demanda (renda/trabalho) -, há razões que se destacam pela sua frequência. Dentro da primeira categoria, quase $85 \%$ da sua frequência se deve à resposta "não quis frequentar escola ou creche", e quase $15 \%$ à resposta "concluiu a série ou curso desejado". Já no interior da segunda, quase $80 \%$ de sua frequência se deve à resposta "trabalhar ou procurar trabalho", aproximadamente $10 \%$ a "ajudar nos afazeres domésticos", e os outros 10\% restantes à "falta de dinheiro para as despesas escolares". Destarte, as categorias agregadas representam bem, respectivamente, a falta de motivação e a entrada no mercado de trabalho como razões para não frequentar a escola.

Assim, se, por um lado, deficiências na oferta parecem responder por uma minoria dos casos, por outro, as limitações econômicas das famílias e, sobretudo, a falta de motivação para frequentar a escola aparecem como as principais razões alegadas para a evasão entre jovens de 15 e 17 anos de idade. Tais resultados reforçam, em certa medida, aqueles extraídos a partir dos modelos logit anteriormente apresentados, nos quais as variáveis de origem familiar (indicadoras de volume de recursos econômicos e culturais) e a situação de trabalho apresentaram efeitos acentuados sobre as chances de evasão. Em sua maioria, os jovens deixam de frequentar a escola não por dificuldades de acesso, mas sim por falta de motivação e, ainda, pela inserção no mercado de trabalho.

Resultados semelhantes a esses foram encontrados em outros países, onde também a falta de motivação se mostrou a razão mais frequentemente mencionada para a evasão (RUMBERGER, 2001). Desse modo, seria plausível imaginarmos que o enorme efeito da origem social sobre as chances de evasão, verificado nos modelos rodados, se dê mais através de sua influência sobre as motivações dos jovens e/ou seus responsáveis do que por meio das restrições objetivas impostas aos mesmos - o que vai ao encontro dos resultados obtidos no "Modelo 06", quando a inserção da variável de participação no mercado de trabalho pouco altera os efeitos das variáveis de capital econômico e cultural. 


\section{Conclusões}

Iniciamos este artigo mencionando a emenda constitucional $n^{\circ}$ 59, de 2009, que tornava a educação básica obrigatória e gratuita dos quatro aos dezessete anos de idade no Brasil, assim como a terceira meta do PNE, que visava universalizar, até 2016, o atendimento escolar para jovens entre 15 e 17 anos de idade. Como vimos, no entanto, ainda em 2015 aproximadamente 15\% dos jovens nessa faixa etária não frequentavam a escola. Nos perguntamos, então, qual seria o peso da origem social e da situação de trabalho sobre as chances de os jovens não frequentarem a escola, e em que medida o efeito da primeira seria mediado pela segunda.

Em consonância com a literatura sobre o tema, brevemente revisada neste artigo, os resultados por nós alcançados tornam evidente o importante papel exercido pelas características socioeconômicas da família de origem sobre as chances de evasão dos jovens. Mesmo quando controlamos por variáveis individuais, geográficas e relativas à composição familiar, o volume de capital econômico e cultural da família de origem exerce forte efeito sobre as chances de os jovens não frequentarem a escola. Vimos também que o fato de o jovem trabalhar, independentemente de seu background domiciliar, eleva significativamente sua chance de evasão, mas apenas quando a carga horária de trabalho é mais intensa. E, finalmente, verificamos que a situação de trabalho não explica parte significativa do efeito de background familiar sobre a evasão escolar.

De tal modo, o modelo teórico empregado por parte da bibliografia nacional, endossado também em reportagens publicadas nos meios de comunicação em massa, e que toma a participação no mercado de trabalho como um dos principais mediadores entre o background familiar e a evasão, deve ser problematizado. De acordo com os resultados alcançados, a situação de trabalho não poderia ser tomada como variável mediadora entre nível socioeconômico e evasão, de modo que ambas são causas assaz importantes, porém pouco relacionadas, da evasão entre jovens. É verdade que jovens com origem em famílias de menor capital cultural e econômico, assim como jovens que trabalham de modo mais intensivo, apresentam chances mais elevadas de evasão; mas, sendo a relação entre background familiar e situação de trabalho menos estreita do que normalmente imaginado, não é a eventual necessidade de trabalhar que explica o efeito da origem social sobre a evasão. Seus efeitos, na verdade, se somam.

Logo, há mecanismos para além da necessidade de trabalhar que são 
os principais responsáveis pela relação entre o background familiar e as chances de evasão. Fora as pressões materiais mais imediatas, é preciso reconhecer a capacidade daquele background condicionar as expectativas, atitudes e preferências dos jovens, assim como sua experiência escolar. Se a evasão deve ser encarada como o ponto de chegada de um longo processo (FINN, 1989), o efeito da origem social dos estudantes sobre a experiência escolar dos mesmos e o modo como esta, por sua vez, é também capaz de estimular ou não um maior engajamento por parte dos jovens devem ser considerados (BRANDÃO et al., 1983).

Ao utilizar os dados do suplemento da PNAD 2006, também fomos capazes de verificar as principais motivações alegadas para a evasão, quais sejam: a entrada no mercado de trabalho, e, principalmente, a falta de motivação dos jovens ou de seus familiares pela continuidade dos estudos. Tais resultados dão suporte àqueles alcançados por meio dos modelos logit, dado que tornam evidente a importância da demanda, muito maior que as deficiências na oferta, para explicar a evasão dos jovens atualmente. Mais do que isso, também nos ajudam a refletir a respeito dos mecanismos por meio dos quais a origem social dos jovens condiciona suas decisões (e/ou de suas famílias) sobre a frequência à escola, indicando que seus efeitos passam mais pelas preferências e motivações do que pelas restrições imediatamente impostas aos jovens.

Conforme já atestado pela literatura internacional a esse respeito, há uma miríade de causas e fatores explicativos para a evasão, muitos deles relacionados entre si, e por isso sendo tão difícil alcançarmos um nível mais satisfatório de compreensão desse fenômeno. Com efeito, para melhor compreender os mecanismos que fazem a mediação entre esses dois polos (origem e frequência à escola) no país, modelos mais completos deverão ser testados, incluindo também as chamadas variáveis endógenas, referentes às aspirações e expectativas dos jovens, seu histórico escolar, a instituição onde estudam etc. ${ }^{25}$ Afinal, como outros trabalhos já identificaram, a evasão é apenas o ponto de chegada de um longo processo.

Apesar de suas limitações, no entanto, o presente estudo tem o mérito de realizar uma análise mais ampla sobre a evasão escolar de jovens no país, revelando não apenas alguns dos principais entraves à expansão da escolarização dos jovens de 15 a 17 anos, mas, ao mesmo tempo, lançando luz

\footnotetext{
${ }^{25}$ Alguns estudos realizados no país, ainda que limitados a um recorte geográfico mais específico, já caminharam nesta direção, como Shirasu e Arraes (2016) e Soares (2015).
} 
sobre um momento decisivo no processo de reprodução das desigualdades. Se não é uma eventual necessidade de trabalhar, supostamente derivada do background social menos abastado de grande parcela da população, o principal motivo a afastar os jovens do sistema de ensino, e nem supostas deficiências na oferta em si, precisamos olhar para dentro das escolas, a fim de encontrar maneiras de torná-las mais atrativas - vis-à-vis o mercado de trabalho - e incentivar o engajamento dos jovens, especialmente para aqueles mais sujeitos à evasão, de modo a melhorar a permanência dos mesmos.

\section{Referências}

ARROY0, Miguel G.

(1993). Educação e Exclusão da Cidadania. In: BUFFA, Ester.; ARROYO, Miguel G.; NOSELLA, Paolo. (orgs.). Educação e Cidadania: quem educa o cidadão. São Paulo: Cortez, p. 31-80.

BARROS, Ricardo Paes de.

(2017). Políticas Públicas para Redução do Abandono e Evasão Escolar de Jovens. São Paulo: Insper. Disponível em: <http:// gesta.org.br/wp-content/uploads/2017/09/ Politicas-Publicas-para-reducao-doabandono-e-evasao-escolar-de-jovens.pdf > Acesso em: 12 fev. 2018.

BRANDÃ0, Carlos Rodrigues.

(1983). Casa de Escola: cultura camponesa e educação rural. Campinas: Papirus.

BRANDÃo, Zaia; BAETA, Anna Maria Bianchini; DA ROCHA, Any Dutra Coelho.

(1983). Evasão e repetência no Brasil: a escola em questão. Rio de Janeiro: Achiamé.

D'AMIC0, Ronald.

(1984). Does employment during high school impair academic progress? Sociology of education, v.57, n.3, p. 152-164. Disponivel em: <http://www.jstor.org/ stable/2112599?seq=1\#page_scan_tab_ contents> Acesso em: 22 fev. 2018.

DE WITTE, Kristof et al.

(2013). A critical review of the literature on school dropout. Educational Research Review, v.10, p. 13-28. Disponível em: <http://www. sciencedirect.com/science/article/pii/
S1747938X13000286> Acesso em: 15 mar. 2017.

DORE, Rosemary; LÜSCHER, Ana Zuleima.

(2013). Permanência e evasão na educação técnica de nível médio em Minas Gerais. Cadernos de Pesquisa, v.41, n.144, p.772789. Disponivel em: <http://publicacoes.fcc. org.br/ojs/index.php/cp/article/view/73>. Acesso em: 10 abr. 2017.

FINN, Jeremy D.

(1989). Withdrawing from school. Review of educational research, v.59, n.2, p.117-142. Disponivel em: <http://rer.sagepub.com/ content/59/2/117.short>. Acesso em: 25 fev. 2017.

HASENBALG, Carlos.

(2003). A Transição da Escola para o Trabalho. In: HASENBALG, Carlos.; SILVA, Nelson Valle. Origens e Destinos. Desigualdades Sociais ao Longo da Vida. Rio de Janeiro: Topbooks, p.147-172.

HASENBALG, Carlos. SILVA, Nelson Valle. (2003). Origens e Destinos: desigualdades sociais ao longo da vida. Rio de Janeiro: Toobooks, p.55-84.

HUNT, Frances.

(2008). Dropping out from school: a cross country review of literature. Create Pathways to Acess Research Monograph, n०16. United Kingdom: Centre for International Education, School of Education, University of Sussex, 2008. Disponivel em: <https://eric. 
ed.gov/?id=ED504047> Acesso em: 20 jan. 2018.

LAMBORN, Susie; NEWMANN, Fred; WEHLAGE, Gary.

(1992). The significance and sources of student engagement. In: NEWMANN, Fred (org.). Student engagement and achievement in American secondary schools. Nova York: Teachers College Press, p.11-39.

LOPES DE LEON, Fernanda L.; MENEZES-FILHO, Naércio Aquino.

(2002). Reprovação, avanço e evasão escolar no Brasil. Pesquisa e Planejamento Econômico, Rio de Janeiro, v.32, n.3, p.417451. Disponivel em: <http://repositorio.ipea. gov.br/handle/11058/4286>. Acesso em: 12 fev. 2017.

MCNEAL Jr., Ralph B.

(1997). Are students being pulled out of high school? The effect of adolescent employment on dropping out.Sociology of Education, v.70, n.3, p. 206-220. Disponivel em: http://repositorio.ipea.gov.br/ handle/11058/4286>. Acesso em: 20 fev. 2018.

MEKSENAS, Paulo.

(1998). Sociologia da Educação: introdução ao estudo da escola no processo de transformação social. 9. ed. São Paulo: Loyola.

MENEZES-FILHO, Naércio; FERNANDES, Reynaldo; PICCHETTI, Paulo.

(2007). Educação e queda recente da desigualdade no Brasil. In: BARROS, Ricardo Paes; FOGUEL, Miguel Nathan; ULYSSEA, Gabriel. (orgs.). Desigualdade de renda no Brasil: uma análise da queda recente. Rio de Janeiro, IPEA, p. 185-304. Disponível em: $\quad<$ http://repositorio.ipea.gov.br/ handle/11058/3249> Acesso em: 25 out. 2012.

NERI, Marcelo.

(2009). 0 Tempo de Permanência na Escola e a Motivação dos Sem-Escola. Rio de Janeiro: FGV/IBRE, CPS.. Disponivel em < http://www. cps.fgv.br/ibrecps/TPE/TPE_Motiva\%C3\%A7 $\%$ C3\%B5esEvas\%C3\%A3oEscolar_Sumario. pdf>. Acesso em: 19 out. 2017.
POWERS, Daniel; XIE, Yu.

(2008). Statistical Methods for Categorical Data Analyses. Bingley: Emerald..

RUMBERGER, R. W.

(1983). Dropping out of high school: The influence of race, sex, and family background. American Educational Research Journal. v.20, n.2, p.199-220. Disponível em: <http://aer. sagepub.com/content/20/2/199.abstract> Acesso em: 15 jan. 2017.

\section{RUMBERGER, Russell W.}

(2001). Why students drop out of school and what can be done. Paper presented at conference on Dropouts in America: How Severe is the Problem? What Do We Know about Intervention and Prevention, in Harvard University. Disponivel em: <https:// escholarship.org/uc/item/58p2c3wp.pdf> Acesso em: 20 jan. 2017.

SCHULTZ, Theodore. W.

(1961). Investment in Human Capital. The American Economic Review, v.51. n.1, p.117. Disponivel em: <http://www.jstor.org/ stable/1818907> Acesso em: 05 dez. 2016.

SHIRASU, Maitê Rimekká; ARRAES, Ronaldo de Albuquerque.

(2016). Determinantes da Evasão e Repetência Escolar. In: Anais do XLIII Encontro Nacional de Economia da ANPEC - Associação Nacional dos Centros de Pós-graduação em Economia. Disponivel em: < https://www.anpec.org.br/ encontro/2015/submissao/files_I/i12-85f3c 3774c3d65741cb278e01e61db39.pdf> Acesso em: 10 fev. 2017.

SILVA, Nelson do Valle.

(2003). Expansão Escolar e Estratificação Educacional no Brasil D. In HASENBALG, C.; SILVA, N.V (Orgs.) Origens e Destinos: desigualdades sociais ao longo da vida. Rio de Janeiro. Toobooks. p. 105-147.

SILVA, Wander Augusto.

(2016). Evasão Escolar no Ensino Médio no Brasil. Educação em Foco, n.19. p.1334. Disponível em: <http://revista.uemg. $\mathrm{br} /$ index.php/educacaoemfoco/article/ view/1910> Acesso em: 04 dez. 2017. 
SOARES, Tufi M. et al.

(2015). Fatores Associados ao Abandono Escolar no Ensino Público em Minas Gerais. Educação e Pesquisa, v.41, n.3, p.757-772, 2015. Disponivel em: <http://www.journals. usp.br/ep/article/view/105654> Acesso em: 05 fev. 2017.

STEINBERG, Laurence; FEGLEY, Suzanne; DORNBUSCH, Sanford M.

(1993). Negative impact of part-time work on adolescent adjustment: Evidence from a longitudinal study. Developmental Psychology, v.29, n.2, p. 171-180. Disponivel em: < http:// psycnet.apa.org/record/1993-29060-001> Acesso em: 21 fev. 2018.

TAVARES JÚNIOR, Fernando; DOS SANTOS, Joan Rosa; DE SOUZA MACIEL, Maurício.

(2017). Análise da Evasão no Sistema Educacional Brasileiro. Revista Pesquisa e Debate em Educação, v.6, n.1, p.73-92. Disponivel em: http://www.revistappgp. caedufjf.net/index.php/revista1/article/ view/142 Acesso em: 10 fev. 2018.

WARREN, John Robert; LEE, Jennifer C.

(2003). The impact of adolescent employment on high school dropout: Differences by individual and labor-market characteristics.
Social Science Research, v.32, n.1, p.98128. Disponivel em: <https://www. sciencedirect.com/science/article/pii/ S0049089X02000212 > Acesso em: 19 fev. 2018.

WARREN, John Robert. (2002). Reconsidering the relationship between student employment and academic outcomes: a new theory and better data. Youth \& Society, v.33, n.3, p.366-393. Disponivel em: <http://journals.sagepub.com/doi/abs/ 10.1177/0044118X02033003002> Acesso em: 24 fev. 2018

WEHLAGE, Gary G. et al.

(1989). Reducing the risk: Schools as communities of support. Philadelphia: Falmer Press.

\section{Recebido em}

fevereiro de 2018

\section{Aprovado em}

setembro de 2018 